\title{
Analysis of Influence on Traffic Before and After Community Opening With Rhine Rivers Community As an Example
}

\author{
Fan $\mathrm{Li}^{1, \text { a }}$ \\ ${ }^{1}$ School of North China Electric Power University, Baoding 071003, China \\ a1662467637@qq.com
}

Abstract: This paper mainly studies the influence of community opening on road access, which is beneficial to perfect urban public service and optimize the structure of street network, so as to realize the maximum utilization of resources. When we study the influence of open area on the surrounding roads, we select the appropriate evaluation index system.

First of all, select the traffic flow, vehicle average speed and traffic density which are used to reflect the traffic capacity. The stronger the capacity, the better the impact of community opening on the surrounding roads. Secondly,taking the Rhine Riverside district of Yibin City, Sichuan Province as an example, combined with the real real-time speed data of the traffic website, the data were pretreated, that is, the late peak 18: 00-19: 30 period, every 15 minutes to record, 7 sets of data were averaged.According to the relationship between vehicle average speed、 traffic volume and traffic density, the specific value of the evaluation index can be quantitatively obtained.Finally, using the analysis of the results, put forward the rationalization of community open.

Key words: Traffic capacity,Traffic flow,Vehicle average speed,Traffic density

\section{Introduction}

As China's population continues to grow, the total number of cars continues to increase, traffic congestion problems are more and more serious[1]. Therefore, to strengthen the planning and construction of neighborhoods, to achieve internal road publicization has become an urgent need to solve the problem[2].

\section{Symbol Description}

\begin{tabular}{c|c}
\hline $\mathrm{T}$ & Traffic flow, car / sec \\
\hline$\beta$ & Distance, meter \\
\hline $\mathrm{x}$ & Car length,meter \\
\hline$V_{o v}$ & Travel speed, $\mathrm{km} / \mathrm{h}$ \\
\hline$S$ & Trip length, $\mathrm{km}$ \\
\hline
\end{tabular}




\begin{tabular}{c|c}
\hline$T_{s}$ & Travel time, hours \\
\hline $\mathrm{N}$ & The number of vehicles in a bicycle section, vehicle \\
\hline $\mathrm{K}$ & Traffic density, vehicle / $\mathrm{km}$ \\
\hline $\mathrm{L}$ & Section length, $\mathrm{km}$ \\
\hline
\end{tabular}

\section{The establishment of traffic index[3]}

\subsection{Traffic flow}

In a certain period of time, the number of vehicles passing through a certain highway point is expressed by a formula:

$$
T=\frac{v_{o v}}{\beta+x}
$$

It can more objectively reflect the heavy traffic, and then show road traffic situation. $T$ value is small, indicating that the road traffic flow is small, traffic ability is good; T value is large, indicating that the road traffic flow is large. Traffic capacity is weak. Traffic conditions are poor.

\subsection{Average vehicle speed}

The average speed of a vehicle in a section can be expressed as follows:

$$
V_{o v}=\frac{S}{T_{s}}
$$

Because $V_{o v}$ is the ratio of the total travel time to the travel time, the travel time includes the actual travel time, the parking time and the time delay (short delay) caused by traffic congestion, road obstruction or other reasons. So, it can be more realistic to reflect the degree of road patency. In the same trip, if $V_{o v}$ is small, it indicates a long trip time; if $V_{o v}$ is large, it indicates that the travel time is short. Assuming that the actual travel time for vehicle is same , the long travel time indicates that the road is not smooth, more delay; otherwise, it shows the road is smooth, less delay.

\subsection{Traffic density}

The traffic density is the number of vehicles per unit length. It represents the degree of concentration of the vehicle distribution. The formula is:

$$
K=\frac{N}{L}
$$




\subsection{The solution of traffic index}

We use the plane map to find out the surrounding road in Yibin City Rhine River area. And we clear its surrounding road structure, then use CAD to draw a simple plan around the district, finally use the relevant traffic service website [4], to collect the road real-time traffic index and car Driving speed. We select the late peak period, that is 18: 00-19: $30 \mathrm{pm}$, every 15 minutes to record a real-time traffic index and car driving speed, a total of 7 Group data. The seven groups of data take the average. As follows:

Figure 1: Yibin City Rhine River district of Sichuan Province

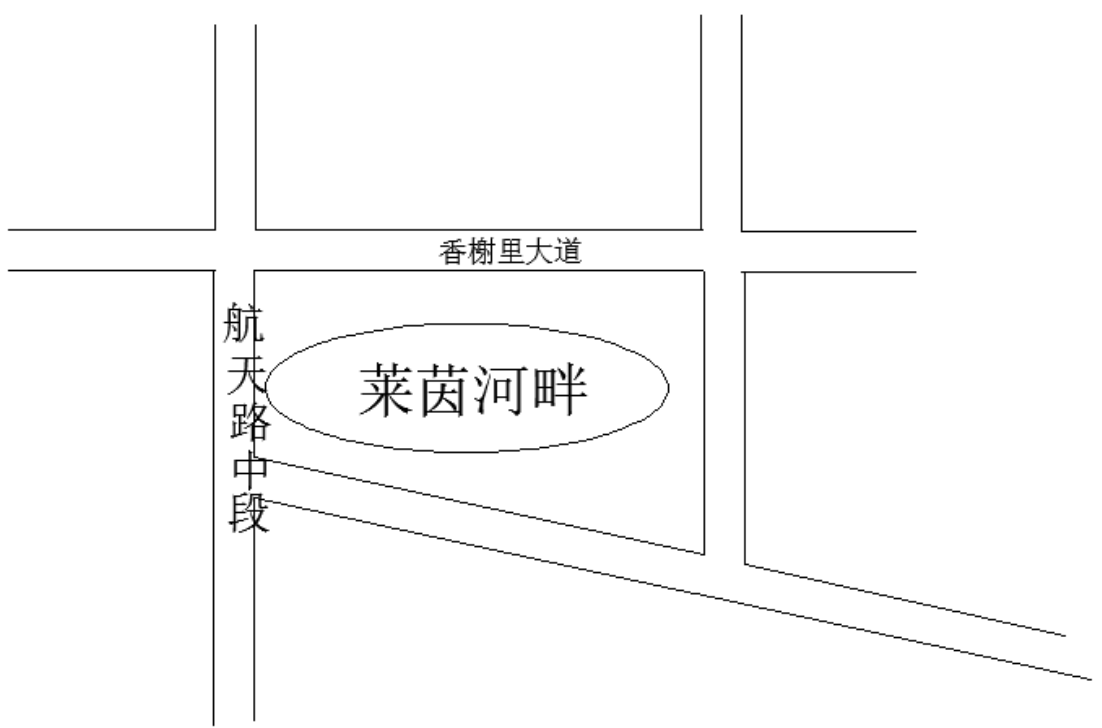

Table1: peak traffic index, driving speed in Yibin City Rhine River district

\begin{tabular}{|c|c|c|c|c|}
\hline & \multicolumn{2}{|c|}{ traffic index } & \multicolumn{2}{c|}{ driving speed $(\mathrm{km} / \mathrm{h})$} \\
\cline { 2 - 5 } & before opening & after opening & before opening & after opening \\
\hline Champs Elysees & 4.5 & 3.9 & 37.3 & 41.8 \\
\hline $\begin{array}{c}\text { Middle of the } \\
\text { aerospace road }\end{array}$ & 7.1 & 5.8 & 20.6 & 29 \\
\hline
\end{tabular}

Table2: Peak traffic indicators in Yibin City Rhine River district

\begin{tabular}{|c|c|c|c|c|c|c|}
\hline \multirow{2}{*}{} & \multicolumn{2}{|c|}{ Travel speed $(\mathrm{km} / \mathrm{h})$} & \multicolumn{2}{c|}{$\begin{array}{c}\text { Traffic line density } \\
\text { (vehicle / km) }\end{array}$} & \multicolumn{2}{c|}{$\begin{array}{c}\text { Traffic flow } \\
\text { (vehicle / h) }\end{array}$} \\
\cline { 2 - 7 } & $\begin{array}{c}\text { before } \\
\text { opening }\end{array}$ & $\begin{array}{c}\text { after } \\
\text { opening }\end{array}$ & $\begin{array}{c}\text { before } \\
\text { opening }\end{array}$ & $\begin{array}{c}\text { after } \\
\text { opening }\end{array}$ & $\begin{array}{c}\text { before } \\
\text { opening }\end{array}$ & $\begin{array}{c}\text { after } \\
\text { opening }\end{array}$ \\
\hline Champs Elysees & 37.3 & 41.8 & 32.17 & 25.1 & 1199.94 & 1049.18 \\
\hline $\begin{array}{c}\text { Middle of the } \\
\text { aerospace road }\end{array}$ & 20.6 & 29 & 58.25 & 35.38 & 1199.95 & 1026.02 \\
\hline
\end{tabular}




\section{Conclusion}

After the opening of the district, from the traffic volume, the average vehicle speed, traffic density point of view, the traffic congestion have a greater ease.So community open benefits more than disadvantages.However, the district can not be open in one step, but should be gradually open. Through the city's planning and management and traffic control measures, to be able to eliminate the hidden dangers of residents,so the open community really achieve the "narrow road, road network dense".

\section{References}

[1] Xia Chaoyang. Urban rail transit and land resources comprehensive development research [D]. Tongji University, 2006.

[2] The CPC Central Committee and State Council issued the "Opinions on Further Strengthening the Management of Urban Planning and Construction" [J]. The State Council of the People's Republic of China Gazette, 2016,07: 6-11.

[3] Wang Ying, Chen Kuangmin, Zhou Yan. Evaluation of Rail Transit Network Based on TOPSIS Model [J]. Journal of Highway and Transportation Research and Development, 2015,06: 130-134.

[4] Sichuan traffic public travel website service system: http: //www.scjtcx.cn/road.jsp, September 10, 2016 